Tohoku J. Exp. Med., 1994, 172, 51-57

\title{
Histological Evaluation of Mixed Mesodermal Tumor of the Ovary
}

\author{
Kоzо Iто \\ Department of Obstetrics and Gynecology, Kinki University \\ School of Medicine, Osaka-Sayama 589
}

Iто, K. Histological Evaluation of Mixed Mesodermal Tumor of the Ovary. Tohoku J. Exp. Med., 1994, 172 (1), 51-57 — Mixed mesodermal tumor (MMT) arising from the ovary is very rare, but we recently encountered two cases of this tumor. The tumors were examined histologically using hematoxylin-eosin, alcian blue, periodic acid-Schiff (PAS), and toluidine blue staining, as well as immunohistochemical staining for S-100 protein. The two patients were postmenopausal women aged 68 and 58 years, respectively. The carcinomatous region of the mixed tumor was endometrioid carcinoma in Patient 1 and serous cystadenocarcinoma in Patient 2, while the sarcomatous region was chondrosarcoma in both patients. The chondrosarcoma tissue was positive for PAS, alcian blue, toluidine blue, and S-100 protein. - mixed mesodermal tumor; ovary; histochemistry; histogenesis

Mixed mesodermal tumor (MMT) arising from the ovary is very rare. According to the review by Hernandz et al. (1977), 93 cases of this tumor have been reported outside Japan. We recently encountered 2 cases of this condition which were studied histologically to examine the histogenesis of primary ovarian MMT.

\section{Case Reports}

The patients were women aged 68 and 58 years. Patient 1 had experienced 4 pregnancies and 4 deliveries, while Patient 2 had experienced 3 pregnancies and 2 deliveries. The chief complaint was right lower abdominal pain in Patient 1 and abdominal distension in Patient 2. Both patients had no noteworthy history of disease or any relevant family history. They had not undergone previous radiotherapy. Menopause occurred at age 45 and 55 years, respectively. Patient 1 consulted an internist in early February 1990 because of pain in the right lower abdominal region. Since the pain was not relieved by medications, the patient was referred to our department on April 9. Patient 2 consulted an internist in early October 1989 because of abdominal distension. Examination revealed that the patient had a gynecological disease, so she was referred to our department on July 31.

In Patient 1, a firm ovarian tumor was palpable in the lower abdominal region, so she was admitted on April 16, 1990. Ultrasonography disclosed a tumor $(18.3 \times 16.0 \times 14.2 \mathrm{~cm})$,

Received September 14, 1993; revision accepted for publication December 22, 1993.

Address for reprints: Kozo Ito, Department of Obstetrics and Gynecology, Kinki University School of Medicine, 377-2 Ohno-Higashi, Osaka-Sayama, Osaka 589, Japan. 
TABLE 1. Clinical characteristics of the patients with mixed mesodermal tumor of the ovary

\begin{tabular}{|c|c|c|c|c|c|c|c|}
\hline Patient & Years & Parity & $\begin{array}{c}\text { Age at } \\
\text { menopause }\end{array}$ & $\begin{array}{c}\text { Chief } \\
\text { complaint }\end{array}$ & $\begin{array}{l}\text { Tumor } \\
\text { marker }\end{array}$ & $\mathrm{CT}$ & MRI \\
\hline 1 & 68 & $\begin{array}{l}\text { Gravia } \\
\text { IV, } \\
\text { para IV }\end{array}$ & 45 & $\begin{array}{l}\text { Right lower } \\
\text { abdominal } \\
\text { pain }\end{array}$ & $\begin{array}{l}\text { CA125 } \\
327 \mu / \mathrm{ml} \\
\mathrm{LDH} \\
1,407 \mu / \mathrm{ml}\end{array}$ & $\begin{array}{l}\text { Irregular } \\
\text { density; } 10.0 \times \\
12.4 \times 17.3 \mathrm{~cm} .\end{array}$ & $\begin{array}{l}\text { Solid in some } \\
\text { parts, cystic in } \\
\text { other parts. } \\
\text { Cyst lumen } \\
\text { had an irregu- } \\
\text { lar pattern. }\end{array}$ \\
\hline 2 & 58 & $\begin{array}{l}\text { Gravida } \\
\text { III, } \\
\text { Para II }\end{array}$ & 55 & $\begin{array}{l}\text { Abdominal } \\
\text { distension }\end{array}$ & $\begin{array}{l}\text { CA125 } \\
596 \mu / \mathrm{ml} \\
\text { LDH } \\
1,092 \mu / \mathrm{ml}\end{array}$ & $\begin{array}{l}\text { Solid tumor; } \\
21.8 \times 18.7 \times \\
15.0 \mathrm{~cm} ; \\
\text { Variable CT } \\
\text { density }\end{array}$ & $\begin{array}{l}\text { Slightly low } \\
\text { intensity } \\
\text { signal on } \\
\text { T1-weighted } \\
\text { images; high } \\
\text { intensity sig- } \\
\text { nal on } \\
\text { T2-weighted } \\
\text { images. }\end{array}$ \\
\hline
\end{tabular}

which was largely cystic and had a few solid areas. MRI revealed a large mass within the pelvic cavity, which had mixed solid and cystic regions. The cyst lumen had an irregular pattern on MRI and the cyst walls in the lower part of the tumor were hypertrophic. Of the tumor markers examined, CA125 was $327 \mathrm{U} / \mathrm{ml}$ and $\mathrm{LDH}$ was $946 \mathrm{U} /$ liter, but the other markers (CEA, CA19-9, etc.) were normal (Table 1). Cytology of ascites collected by culdocentesis was positive, and the cells in the ascites were considered to be deriving from an adenocarcinoma.

Laparotomy disclosed metastases within the abdominal cavity and massive ascites. The tumor arose from the right ovary and the ovary was firmly attached to the retroperitoneum, rectum, uterus, and anterior abdominal wall. Partial resection of the ovary, abdominal wall, and greater omentum was performed. The disease was classified as stage IV at operation (Table 2).

When the resected tissues were examined, the tumor tissue arising from the right ovary extended to the Douglas pouch and to the abdominal wall. A large tumor was also noted in the greater omentum. The wall of the cystic part of the right ovarian tumor was relatively thick and was adherent to the surrounding organs. The cyst lumen showed papillary proliferation.

In Patient 2, a hard mass was palpable in the pouch of Douglas, so she was admitted on August 18, 1989. On admission, CT scans revealed a tumor $(21.8 \times 18.7 \times 15.0 \mathrm{~cm})$ which was mainly solid and also had a cystic component. The CA126 level was $596 \mathrm{U} / \mathrm{ml}$ and LDH was 1,092 U/liter. The other tumor markers such as CEA and CA19-9 were normal (Table 1). Cytology of ascites collected by culdocentesis was positive, and the cells in the ascites were diagnosed as adenocarcinoma.

Laparotomy disclosed metastases within the abdominal cavity and massive ascites. The ovarian tumor was firmly attached to the retroperitoneum, rectum, uterus, abdominal wall, and greater omentum. Partial resection of the ovary, abdominal wall, and greater omentum was performed. The tumor was clinically classified as stage III (Table 2).

When the resected tissues were examined, the tumor arising in the ovary was continuous with the lesions in the pouch of Douglas and the intestine. Tumor was also noted in the greater omentum. The ovarian tumor was soft, fragile, and hemorrhagic.

In Patient 1, $100 \mathrm{mg}$ of CDDP was administered intraperitoneally during surgery. 
TABLE 2. Clinical course of the two patients with mixed mesodermal tumor of the ovary

\begin{tabular}{clccc}
\hline & \multicolumn{1}{c}{ Surgery } & Stage & Histological diagnosis & Course \\
\hline Patient 1 & $\begin{array}{l}\text { Partial tight oophorectomy } \\
\text { Omentectomy }\end{array}$ & IV & $\begin{array}{c}\text { Endometrioid carcinoma \& } \\
\text { chondrosarcoma }\end{array}$ & Death \\
Partial resection of abdominal & wall tumor & & & \\
Patient 2 & $\begin{array}{l}\text { Partial oophorectomy } \\
\text { Omentectomy }\end{array}$ & III & $\begin{array}{c}\text { Serous cystadenocarcinoma } \\
\text { \& chondrosarcoma }\end{array}$ & Death \\
\hline
\end{tabular}

Subsequently, Cyclophosphamide-Adriamycin-Cisplatin (CAP) therapy was administered to a total CDDP dose of $425 \mathrm{mg}$. On September 26, 1990, the patient underwent a secondlook operation which included simple total hysterectomy, excision of the bilateral uterine appendages, excision of parts of the small intestine, and partial resection of the pouch of Douglas tumor. At operation, $100 \mathrm{mg}$ CDDP was administered intraperitoneally, and this was followed by one cycle of CAP therapy. After surgery, the patient received oral $5^{\prime}$ DFUR therapy and the CA19-9 and CEA levels were monitored. She later developed renal dysfunction followed by general deterioration and died on August 26, 1991.

In Patient 2, $100 \mathrm{mg}$ of CDDP was administered intraperitoneally at laparotomy. Subsequently, CAP therapy was administered to a total CDDP dose of $430 \mathrm{mg}$. The patient underwent a second-look operation on December 13. The residual tumor was very large and could only be resected partially. After surgery, $25 \mathrm{mg}$ of VP-16 was injected intraperitoneally on a daily basis. However, the patient died on August 5, 1990.

\section{Results}

\section{Histological findings}

Hematoxylin-eosin (HE) staining. In Patient 1, the epithelial component of the tumor had the features of endometrioid carcinoma. Endometrial glandular structures were formed by cells that featured irregular nuclei, marked atypia, and mitotic figures (Fig. 1).

In Patient 2, the epithelial component of the tumor had the features of serous cystadenocarcinoma. Glandular structures were again formed by cells with irregular nuclei and were markedly atypical that demonstrated numerous mitotic figures (Fig. 2).

Alcian blue staining. Periodic acid-Schiff (PAS) staining. Toluidine blue staining. In both patients, the nonepithelial component of the tumor had the features of chondrosarcoma. The cartilage-like tissues contained highly atypical cells, which had irregular pachychromatic nuclei and large red nucleoli (Figs. 1 and 2).

\section{Immunostaining for $\$ 100$ protein}

The tissue showing proliferation of chondrosarcoma cells was positive for S100 protein, in addition to alcian blue and PAS (Fig. 3).

Table 3 summarized the staining pattern of the different tissues for PAS, 

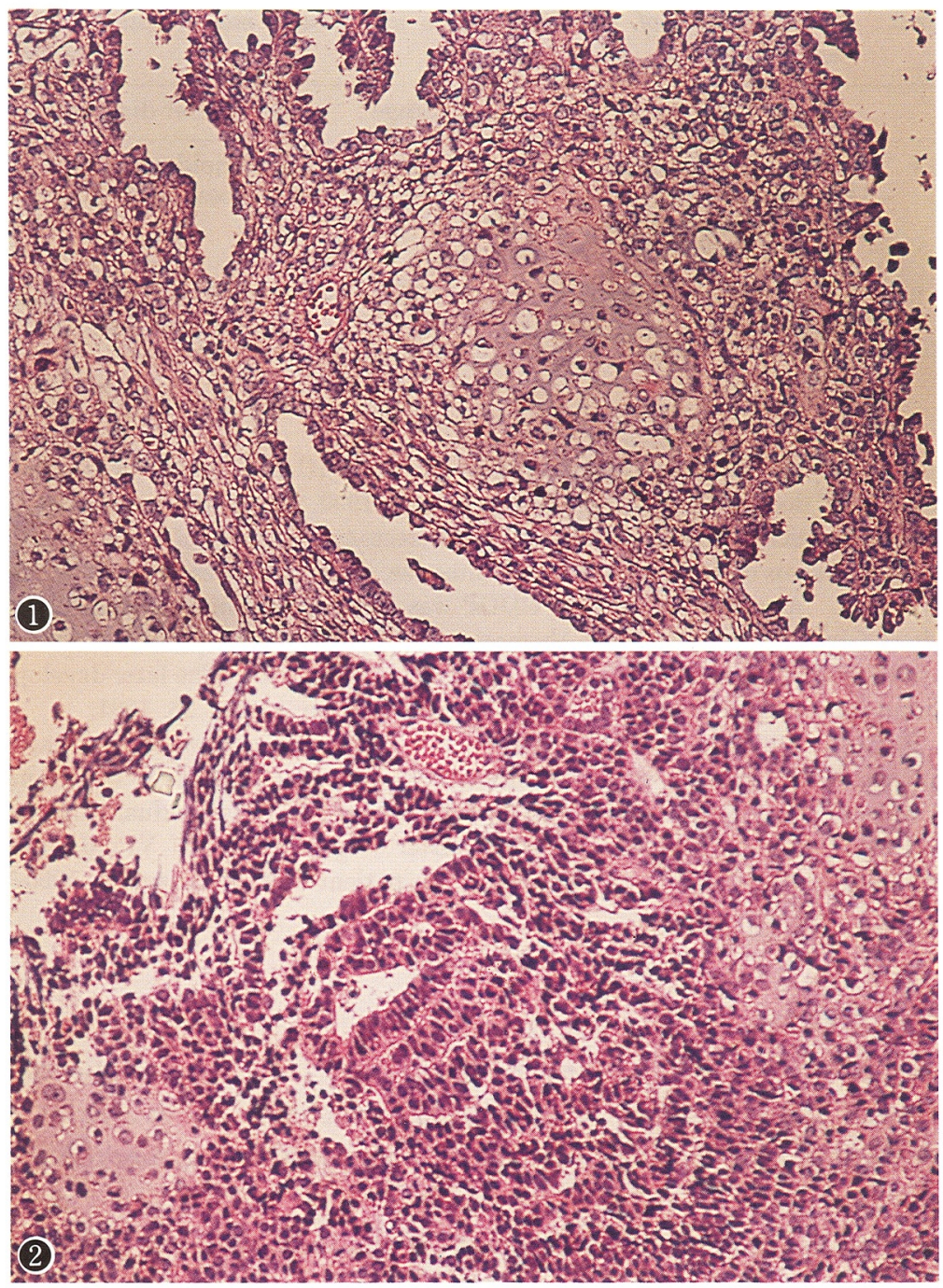

Fig. 1. Endometrioid carcinoma and chondrosarcoma $(\mathrm{HE}, \times 100)$. Patient 1.

Fig. 2. Serous cystadenocarcinoma and chondrosarcoma $(\mathrm{HE}, \times 100)$. Patient 2.

TABLE 3. Staining patterns of the two mixed mesodermal tumors of the ovary

\begin{tabular}{lccc}
\hline & Chondrosarcoma & $\begin{array}{c}\text { Endometrioid } \\
\text { carcinoma }\end{array}$ & $\begin{array}{c}\text { Serous } \\
\text { cystadenocarcinoma }\end{array}$ \\
\hline PAS & + & + & - \\
Alcian blue & + & - & - \\
Toluidine blue & + & - & - \\
S-100 protein & + & - & - \\
\hline
\end{tabular}




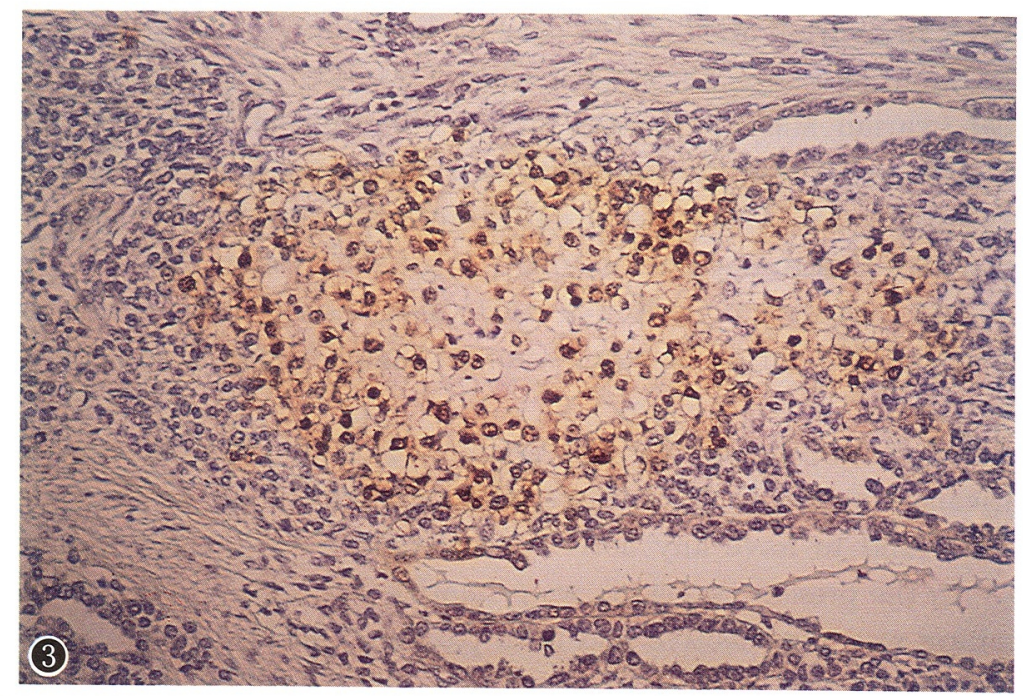

Fig. 3. Chondrosarcoma (S-100 protein, $\times 100$ ). S-100 protein staining is positive.

alcian blue, toluidine blue, and S100 protein. The chondrosarcomatous tissue was positive for all stains, the endometrioid carcinoma was only positive for PAS, and the serous cystadenocarcinoma was negative for all stains.

\section{Discussion}

MMT is a highly malignant lesion which involves the proliferation of a mixture of carcinoma and sarcoma. It often occurs in the uterine body and its incidence decreases in the order of uterine cervix, ovary and oviduct (Ober and Black 1955; Hernandz et al. 1977; Lele et al. 1980). According to the WHO classification, this lesion is an endometrioid tumor and thus belongs to the epithelial tumors (Serov et al. 1973). Barwick and Livolsi (1980) reported that this tumor accounts for $1 \%$ or less of ovarian tumors. Hernandz et al. (1977) found that ovarian MMT was associated with a history of radiotherapy in only 2 out of 101 cases, and that the causal relationship observed between uterine MMT and radiotherapy was absent for ovarian MMT. Dehner et al. (1971) have reported that the mean age of onset for primary ovarian MMT was 53 years, and that this tumor frequently occurs in postmenopausal nullipara and is very rare in women under 40 years of age. The ages of our present two cases (58 and 68 years) support the data reported by Dehner et al. (1971).

Macroscopically, MMT takes the form of multilocular cyst, that is often accompanied by solid tissue. The maximum diameter of this tumor averages about $15 \mathrm{~cm}$ in many reports (Dehner et al. 1971; Fenn and Abell 1971; Barwick and Livolsi 1980). The clinical stage at the time of detection is thought to be the most important prognostic factor. Fenn and Abell (1971) reported that the 
clinical stage of ovarian MMT at the time of detection was III or IV in 10 out of 20 cases. In our two cases, the stage was also III or IV. Ortega et al. (1978) have stated that ovarian MMT progresses rapidly like uterine MMT, and that it has often invaded the intrapelvic structures or metastasized to extrapelvic organs by the time of diagnosis. Dehner et al. (1971) reported that the 1-year survival rate of patients with this tumor was only $20 \%$, that the average survival period was 6 months, and that its prognosis was worse than that of carcinosarcoma. However, if ovarian MMT can be detected before it begins to spread, the prognosis may be improved.

Regarding chemotherapy for this tumor, Lele et al. (1980) assessed the effect of 14 anticancer agents in 35 patients with ovarian MMT. In their study, few drugs were found to have any activity, and only VAC therapy was relatively effective. In the present two cases, we primarily used CDDP (CAP therapy), but chemotherapy was not effective and both patients died.

Histologically, the epithelial component of this tumor is often an adenocarcinoma showing varying degrees of differentiation and squamous metaplasia (Dehner et al. 1971). Our two cases were classified as endometrioid carcinoma and serous cystadenocarcinoma, respectively. The nonepithelial component often shows features of rhabdomyosarcoma and chondrosarcoma (Dehner et al. 1971; Barwick and Livolsi 1980), and our two cases had chondrosarcoma lesions.

Regarding the histogenesis of uterine carcinosarcoma, Norris and Taylor (Norris and Taylor 1966) have proposed that it is a combined tumor arising from the Mülerian duct, i.e., from the multipotent cells of the endometrial stroma. This view is based on the known multipotential nature of endometrial stromal cells. Bartsich et al. (1967) have supported the hypothesis of Norris and Taylor, although they did also not rule out the possibility that uterine carcinosarcoma is a composite tumor. On the other hand, both MacFarlane and Pritchard (1954) and Willis et al. (1953) considered that endometriosis was involved in the development of ovarian MMT because the ovary is not embryologically derived from the Müllerian duct. However, their hypothesis has been refuted by numerous investigators, since the detection of endometriosis in patients with ovarian MMT is rare. Furthermore, this tumor often occurs in elderly individuals after menopause, so any associated endometriosis would not be very active. Therefore, the development of ovarian MMT from endometriosis appears to be unlikely in most cases at least. Based on the finding that the epithelium of the ovarian surface originates (like the endometrium) from the body cavity epithelium which develops from the Müllerian duct, Dehner et al. (1971) and Ortega et al. (1978) have speculated that ovarian MMT arises from undifferentiated multipotential cells that develop from the mesoderm of the Müllerian duct epithelium.

In our two cases of primary ovarian MMT, the coexistence of carcinoma and sarcoma was histologically observed. The carcinomatous component had the features of endometrioid carcinoma in one case and of serous cystadenocarcinoma 
in the other case, while the sarcomatous component had the features of chondrosarcoma in both cases. Thus, this lesion was suggested to be a combined tumor which developed from undifferentiated multipotential cells that were derived from the mesoderm and were located in or immediately below the ovarian capsule.

\section{References}

1) Bartsich, E.G., O'leary, J.A. \& Moore, G.J. (1967) Carcinosarcoma of the uterus. A 50 year review of 32 cases (1917-1966) Obstet. Gynecol., 30, 518-523.

2) Barwick, K.W. \& Livolsi, V.A. (1980) Malignant mixed mesodermal tumors of the ovary. Am. J. Surg. Pathol., 4, 37-42.

3) Dehner, L.P., Norris, J.H. \& Taylor, H.B. (1971) Carcinosarcomas and mixed mesodermal tumors of the ovary. Cancer, 27, 207-216.

4) Fenn, M.E. \& Abell, M.R. (1971) Carcinosarcomas of the ovary. Am. J. Obstet. Gynecol., 110, 1066-1074.

5) Hernandz, W., Disaia, P.J., Morrow, C.P. \& Townsend, D.E. (1977) Mixed mesodermal sarcoma of the ovary. Obstet. Gynecol., 49, 59-63.

6) Lele, S.B., Piver, M.S. \& Barlow, J.J. (1980) Chemotherapy in management of mixed mesodermal tumors of the ovary. Gynecol. Oncol., 10A, 298-302.

7) MacFarlane, K.T. \& Pritchard, J.E. (1954) Two cases of Müllerian carcinosarcoma. Am. J. Obstet. Gynecol., 68, 652-658.

8) Norris, H.J. \& Taylor, H.B. (1966) Mesenchymal tumors of the uterus. III. A clinical and pathologic study of 31 carcinosarcomas. Cancer, 19, 1459-1465.

9) Ober, W.B. \& Black, M.B. (1955) Neoplasms of the subcoelomic mesenchyme. Arch. Path., 59, 698-705.

10) Ortega, I., Nolgales, F.F., Amerigo, J.J. \& Fernandez, J. (1978) Carcinosarcomas and mixed mesodermal tumors of the ovary: A clinicopathologic study of six cases. Int. J. Gynecol. Obstet., 15, 561-565.

11) Serov, S.F., Scully, R.E. \& Sobin, L.H. (1973) Histological typing of ovarian tumors. World Health Organization International Histological Classification of Tumors, No. 9, Geneva, pp. 17-18.

12) Willis, R.A. (1953) Structure \& growth of tumors. In: Pathology of Tumors, edited by R.A. Willis, London, Butterworth. pp. 139-141. 